\title{
RESENHA
}

\section{OLIVEIRA, RENATA FERREIRA DE. ÍNDIOS PANELEIROS DO PLANALTO DA CONQUISTA: DO MASSACRE E O (QUASE) EXTERMÍNIO AOS DIAS ATUAIS. SALVADOR: SAGGA, 2020.}

\author{
Por Pbilipe Murillo Santana de Carvalho*
}

O valor da história nas sociedades se mensura na constatação de qual o peso do passado em nosso presente e nosso futuro. E aqui se não se trata apenas do comum aforisma de que aprender com o passado é caminhar para um futuro melhor. O exercício fundamental do historiador é analisar de que maneira o passado, em discurso ou simbolismo, pesa, por vezes sob a forma de trauma na vida cotidiana dos indivíduos ou de um mal-estar persistente no coletivo social. O valor simbólico da história é se defrontar com a perspectiva da construção - ou da desconstrução - da memória enquanto discursos que se organizaram - e se organizam - em face das hierarquias sociais e das diferenças culturais. Nesses termos, como salienta Michel Pollak (1989), a memória é uma força social ativa, dinâmica, seletiva que se define pelas demandas do presente como instrumento e objeto de poder.

A memória que se sustenta nos estereótipos dos derrotados em favor daqueles considerados vencedores na civilização ocidental ergue-se sob a narrativa de um passado "mal-dito", surgindo por vezes como se fosse a história única e inquestionável. O passado que se fundamenta nos silenciamentos das diferenças e das violências das disputas possivelmente formará uma geração de pessoas recalcadas, que banalizarão as perversidades a partir de uma memória “inter-ditada”. Em ambos os casos, a memória se torna terreno fértil para o cultivo do ressentimento, do ódio e da banalização da maldade, como nos lembra Francisco Carlos Teixeira da Silva (2013). O fardo do passado e suas narrativas se traduzem em silenciamentos das violências e apagamentos das resistências de mulheres, de homossexuais, de negros, de índios, ou daqueles a quem a memória social seletivamente escapou. Em particular, é deste passado e das memórias dos povos e a da cultura indígenas do sudoeste da Bahia que a historiadora Renata Ferreira de Oliveira trata em sua obra "Índios Paneleiros do Planalto da Conquista: do massacre e o (quase) extermínio aos dias atuais". * Professor do Instituto Federal da Bahia (IFBA). Doutorado em História pela Universidade Federal da Bahia (UFBA). Email:
philipe@ifba.edu.br 
O livro, publicado pela Editora Sagga em 2020, é amparado pela pesquisa de mestrado na Universidade Federal da Bahia, cuja prioridade foi a análise e a recuperação da memória e da identidade indígenas da Batalha, região do Planalto da Conquista, no sudoeste baiano. Atualmente, os povos indígenas são dados por exterminados pela sociedade conquistense nas guerras entre colonos portugueses e Kamakã-Mongoió, em fins do século XVIII e inícios do XIX. Inquieta diante desta narrativa enviesada da vitória do branco colonizador, Renata Ferreira de Oliveira se pergunta: "como poderiam ter sumido se conheci uma descendente que habita essa região histórica?”.

A obra se inicia com uma revisita crítica à memória que narra as origens da cidade de Vitória da Conquista a partir da derrota dos Pataxós, Mongoiós e Ymboré para as tropas do sertanista João Gonçalves da Costa e do mestre de campo João da Silva Guimarães. Sua pesquisa retoma o projeto colonizador para a região do "Sertão da Ressaca", área que se localizava entre os rios Pardos e de Contas, rica em matas e avizinhada do litoral.

Em meados do século XVIII, a Coroa portuguesa estimulou a expansão das fronteiras de ocupação em direção ao interior de seus territórios na América. O objetivo era encontrar novas minas de metais ou pedras preciosas, estabelecer fazendas de gado, assassinar índios que se opunham ao povoamento, aldear os que aceitassem e destruir quilombos. O contraste entre o espírito cruzadista dos bandeirantes e as culturas indígenas ali presentes demarcaram as disputas - materialmente desiguais - da colonização. A imposição da civilização católica e portuguesa se traduziu em políticas de "pacificação" com aldeamento dos indígenas ou na "guerra justa" contra aqueles que resistiram à colonização, taxados pelos bandeirantes como bárbaros. Mais tarde, essa licença histórica não deixou de ser utilizada numa memória política que anistiava o massacre dos índios em favor do "ato civilizatório" dos sertanistas, que resultaria na cidade de Vitória da Conquista. Nesse sentido, a historiadora Renata Oliveira se aproxima dos resultados de pesquisa histórica da professora Maria Aparecida Sousa (2001), ao ressaltar que o avanço do projeto colonizador no Sertão da Ressaca implicou na desestruturação das comunidades indígenas, com apresamento para exploração da força de trabalho e massacre das aldeias resistentes à dominação luso-católica

No entanto, Renata Oliveira sublinha as reações e as estratégias dos povos indígenas diante da expansão colonial, ao dialogar com uma história social indígena recente. Sua obra recupera a agência dos nativos frente à política indigenista dos colonos, quer se tornando aliados dos brancos para sobreviver e atacar grupos rivais, quer para resistirem, ao seu modo, às imposições dos sertanistas já no século XVIII. Os Mongoiós conscientes do seu papel para o projeto colonizador dos portugueses, aliavam-se com os colonos não apenas para manter relações amistosas de sobrevivência, mas também para delatar Botocudos e Pataxós - rivais étnicos - aos sertanistas.

Havia, também, roubos, fugas e assassinatos praticados pelos indígenas contra os colonos que adentravam os sertões - incluindo aí seus aliados circunstanciais -, que impunham o controle social, o trabalho compulsório e os privavam do acesso à terra e aos rios. Conforme seus interesses, os indígenas aldeados pelos portugueses constituíram uma relação que oscilava entre a aliança com os projetos 
coloniais e a sua negação. Nesse sentido, a obra mostra que as comunidades indígenas agiam de acordo com as circunstâncias históricas e, portanto, não estavam submissos e passivos diante da dinâmica da colonização. Em sintonia com o que ressalta a historiadora Manuela Carneiro da Cunha (2012, p. 25), há na pesquisa de história social a busca por entender como "as sociedades indígenas pensaram o que lhes acontecia em seus próprios termos, reconstruíram uma história de mundo em que elas pesavam e em que suas escolhas tinham consequências". Neste particular, a historiadora Renata Oliveira defende que essa complexa relação colonizador-povos indígenas desconstrói o mito de fundação de Vitória da Conquista, pautada na ideia de que os "gentios bárbaros" foram sempre um empecilho à "civilização", dado que, sem a informação e a colaboração de grupos aliados, a conquista dos portugueses poderia ter ganhado outros contornos.

É nesta contraposição de memórias sobre as origens da cidade de Vitória da Conquista que a autora tece o segundo capítulo de seu livro. $\mathrm{O}$ mito fundador da cidade foi construído na heroicização do sertanista João Gonçalves da Costa, que, ao enfrentar a resistência de mais de 300 índios KamakãsMongoiós, teria vencido a batalha já com 80 anos de idade e contando com apenas 50 soldados. Em retribuição à conquista, o bandeirante teria ordenado a construção da igreja matriz em homenagem a Nossa Senhora das Vitórias. Esta foi uma memória cultivada na ideia da "Guerra Justa”, uma vez que o ódio ao índio foi temperado com o discurso dos nativos como seres "bárbaros", "violentos" e "bravios". Este enredo mal-dito instrumentaliza a construção de uma memória que torna herói os sertanistas e seus descendentes, sacralizando sua violência por meio de uma indulgência em favor do surgimento da cidade. Ao mesmo tempo, demarca o início do fim da história e da cultura das comunidades indígenas no Planalto da Conquista.

A vitória de João Gonçalves da Costa na batalha mítica é também o ponto de partida do desaparecimento destinado aos indígenas do Planalto da Conquista. Em sentido contrário, o destino manifesto de Vitória da Conquista como civilização, resultado do empenho colonial do bandeirantismo, foi fortalecido pelos memorialistas já em tempos de República, do século XX. Historiadores, poetas e políticos reiteraram em verso e prosa a conotação dos indígenas como antropófagos, violentos e pagãos, obstáculos à civilização, ao passo em que os sertanistas e seus descentes foram apresentados como pioneiros da sociedade conquistense. Renata Oliveira destaca que, não por acaso, esta memória dos heróis sertanistas se assentava nos tempos em que seus descendentes ocupavam novos territórios no Planalto da Conquista e se tornavam coronéis da cidade, já em tempos de República no Brasil.

Esta memória foi escrita em monumentos e símbolos oficiais espalhados pela cidade. Um destes lugares de memória hegemônica destacados pela autora é o Monumento aos Bandeirantes, inaugurado em 1940 pelo prefeito Régis Pacheco (mais tarde, governador da Bahia) e fincado no Jardim das Borboletas (atual Praça Tancredo Neves), local em que estaria localizado um antigo cemitério indígena. À época, este monumento celebraria a atuação heroica dos sertanistas na fundação da cidade - uma verdadeira ode à civilização -, o que nos faz lembrar uma das teses da história de Walter Benjamim: Todo monumento à civilização é também à barbárie (LÖWY, 2005, p. 77). 
A autora encerra o segundo capítulo com a análise das narrativas históricas escritas na década de 1970 e 1980. Apesar de apontarem para uma visão crítica sobre os bandeirantes da região, em que se destaca o genocídio praticado pelos sertanistas, os intelectuais e escritores mais recentes persistem em partir do episódio da Batalha como início do extermínio dos povos indígenas da cidade de Vitória da Conquista. Para Renata Ferreira, há uma memória hegemônica que, em diferentes momentos históricos, por um tempo enalteceu o colonizador como agente da civilização, e, posteriormente, passou a vitimizar o índio, colocando-o como um sujeito em extinção decorrente do genocídio. Em ambos os casos, a existência histórica dos povos indígenas se constituiu numa memória subterrânea, enterrada no passado da cidade. É uma memória enraizada em antiga historiografia brasileira que reservava - e ainda persiste em reservar - aos índios o lugar do passado, como salientou Maria Regina Celestino de Almeida (2010, p. 17).

O capítulo III do livro caminha no sentido de retomar as memórias dos moradores da Batalha como um "Contraponto Indígena" à memória dos colonizadores da cidade de Vitória da Conquista. A disputa pela narrativa do passado é atravessada pelos significados que as comunidades descendentes dos povos indígenas da Batalha atribuem à circulação da memória hegemônica. Como afirma Renata Oliveira, mesmo quando reconhecem a derrota na guerra, há uma memória que aponta para as violências e as resistências dos ancestrais indígenas. O passado de violência e de superação dos indígenas é o ponto de partida para recuperação da identidade e do território dos descendentes no Planalto da Conquista.

Para as comunidades da Batalha, a memória da Guerra da Batalha é reconstituída nos traumas das crueldades praticadas pelos colonizadores, particularmente nas práticas do sequestro, estupro e morte das Kurukas - termo para criança no vocabulário Gren/Botocudo - pelos sertanistas. Contudo, recuperase também as histórias de reação a esta violência, como no caso do coronel Bitonho, um dos caçadores de índios, que, após roubar uma kuruka e tentar violentá-la sexualmente, recebeu a reação da pequena índia. Por este motivo, o coronel teria assassinado a criança com um facão. Reza a lenda indígena que o coronel Bitonho teria encontrado um tatu numa das caças em sua propriedade e que, ao tentar matar o animal, acidentou-se fatalmente com o mesmo facão com o qual teria assassinado a indiazinha. Segundo Renata Oliveira, as comunidades indígenas relatam que este episódio da morte do caçador teria sido provocado pelo encantamento da indiazinha no tatu, o que "marca, nas narrativas sobre a guerra, um processo de resistência evidenciado dentro e foram do âmbito da violência”. (p. 124)

Cruzando os relatos de história oral dos moradores da região da Batalha com fontes escritas dos arquivos do judiciário, Renata Oliveira reconstruiu uma trajetória das ocupações indígenas nos arredores da antiga Vila Imperial de Vitória da Conquista no século XIX. O que mostra que mesmo após as guerras com os sertanistas, os diferentes povos indígenas se reacomodaram em outras terras. A ocupação das terras era atravessada pelos constantes conflitos com fazendeiros, que, por sua vez, sustentados por uma memória hegemônica de extermínio dos índios, negavam a ligação entre terra e etnicidade dos descendentes indígenas no Planalto da Conquista. Um dos pontos fortes desta pesquisa histórica é mostrar as conexões das lutas históricas dos indígenas nesta região com o surgimento de formas de 
organização contemporâneas, como a Associação de Moradores da Batalha, as Comunidades Eclesiais de Base e o Partido dos Trabalhadores, em Vitória da Conquista, na década de 1980.

O contraponto indígena desta memória é construído com outros importantes pilares da identidade cultural dos moradores da Batalha: as crenças e as práticas. Nos depoimentos, o uso de ervas e de rezas para curas são relatados como aprendizados de um conhecimento transmitidos dos ancestrais dos "tempos das guerras". Ao seu modo, estas comunidades reinventam sua própria concepção de tempo, ao dividir seu passado entre o "tempo da guerra", o "tempo dos antigos" e seus desdobramentos sobre sua identidade cultural atual.

Outro símbolo importante das crenças e das práticas que atravessam a memória dos moradores da Batalha é o trabalho com barro e a produção de panelas de cerâmica. Neste aspecto, as reminiscências das índias que moldavam panelas deram, inclusive, o signo de identidade para a descendência, uma vez que os moradores daquela região ficaram conhecidos como Paneleiros. Sob influência do olhar histórico antropológico tratado por João Pacheco de Oliveira, a autora destaca que "com a argila, elas moldavam a cultura e a identidade da Batalha" (p. 153).

Em sua obra, Renata Oliveira percorreu as trilhas subterrâneas da memória indígena do Planalto da Conquista, as quais ainda são constantemente sobrepostas pelo silenciamento ou negação impostas pelas memórias da civilização conquistense. A autora recompôs historicamente a construção da memória social indígena dos paneleiros do Planalto da Conquista, observando de que maneira suas narrativas, suas crenças e suas práticas, transmitidas dos ancestrais, dos "tempos das guerras", articulam-se na autoafirmação de sua identidade étnica atualmente.

No caso particular da cidade de Vitória da Conquista, além da memória hegemônica que institui o mito de fundação da cidade no suposto heroísmo dos sertanistas, há, em paralelo, a tecitura de uma identidade que enaltece a "Suíça Baiana", espécie de versão atualizada da valorização cultural branca, europeizada e colonial. Por tudo isso, a obra "Índios Paneleiros do Planalto da Conquista" é fundamental para demarcar não apenas a identidade indígena daquele lugar, mas do direito à memória e do direito à terra numa sociedade que insiste em pôr a história dos povos indígenas no passado. Do ponto de vista psicanalítico, a recuperação das tradições e da cultura indígena na forma de regressão histórica e de (des)construção da memória coletiva a partir de rica pesquisa acadêmica transforma-se num ato de emancipação, não só porque preserva narrativas, crenças e práticas, mas também porque estimula nossa reflexão sobre a pluralidade da identidade de Vitória da Conquista e - por que não - da Bahia.

A pesquisa ora publicada pela professora Renata Oliveira encara os novos desafios da história indígena no Brasil, que, como salienta Francisco Cancela, inspirado pelo historiador John Monteiro, não se reduz a preencher o lugar dos nativos, mas, em especial, contribuir para dissolver os estereótipos e as narrativas que assentam a violência e o silenciamento dos indígenas no Brasil. (CANCELA, 2016, p. 22) Em sintonia com isso, esse livro nos permite aprender com o relato do senhor Adelino Oliveira, um dos anciões da região da Batalha, que disse: "quando passa a saber quem eram eles [os ancestrais indígenas], descobrem quem somos nós". 


\section{Referência Bibliográfica}

CANCELA, F. Velhos e novos desafios da história indígena. In: SANTOS, F. L. Os indios na bistória da Babia. Cruz das Almas: Ed. da UFRB; Belo Horizonte: Fino Traço, 2016. p. 13-22

ALMEIDA, M. R. C. Os indios na história do Brasil. Rio de Janeiro: Ed. da FGV, 2010.

CUNHA, M. C. da. Índios no Brasil. São Paulo: Claro Enigma, 2012.

LÖWY, M. Walter Benjamin: aviso de incêndio: uma leitura das teses "Sobre o Conceito de História". São Paulo: Boitempo, 2005.

POLLAK, M. Memória, Esquecimento e Silêncio. Estudos históricos, v. 2, n. 3, p. 3-15, 1989.

SILVA, F C T. da. Reconstruindo as fronteiras: a ressurgência do fascismo na Alemanha (O caso de Zwickau, 2011-2012). Diversitas, ano I, n. 1, p. 29-49, mar.-set. 2013.

SOUSA, Maria Aparecida Silva de. A conquista do sertão da ressaca: povoamento e posse da terra no interior da Bahia. Vitória da Conquista, BA: Edições UESB, 2001. 